\title{
A novel mutation of the MEN1 gene in a Japanese kindred with familial isolated primary hyperparathyroidism
}

\author{
Munehiro Honda ${ }^{1,2}$, Toshihiko Tsukada ${ }^{2}$, Hiroko Tanaka ${ }^{1}$, Kouji Maruyama ${ }^{2}$, Ken Yamaguchi ${ }^{2}$, Takao Obara ${ }^{3}$, \\ Tohru Yamaji ${ }^{4}$ and Miyuki Ishibashi ${ }^{1}$ \\ ${ }^{1}$ Fourth Department of Medicine, Teikyo University School of Medicine, Kawasaki, Kanagawa, Japan, ${ }^{2}$ Growth Factor Division, National Cancer \\ Research Institute, Chuo-ku, Tokyo, Japan, ${ }^{3}$ Department of Surgery, Institute of Clinical Endocrinology, Tokyo Women's Medical College, Shinjuku-ku, \\ Tokyo, Japan and ${ }^{4}$ Odawara Hospital, Printing Bureau, Ministry of Finance, Odawara, Kanagawa, Japan
}

(Correspondence should be addressed to M Ishibashi, Fourth Department of Medicine, Teikyo University School of Medicine, 3-8-3 Mizonokuchi, Takatsu-ku, Kawasaki, Kanagawa 213-8507, Japan)

\begin{abstract}
Objective: To determine whether familial isolated hyperparathyroidism (FIHP) is a variant of multiple endocrine neoplasia type 1 (MEN1) we analyzed the MEN1 gene in such a kindred.

Design and methods: The study included the 70-year-old proband and nine relatives. Blood was drawn for biochemical evaluation and germline mutation analysis by direct sequencing of the MEN1 gene amplified by PCR. A hyperplastic parathyroid gland obtained from a family member served for a loss of heterozygosity (LOH) study.

Results: Three members from two generations in this kindred were found to have primary hyperparathyroidism, while none had clinical or biochemical evidence of MEN1, MEN2 or hyperparathyroidismjaw tumor syndrome. Analysis of germline DNA in the proband showed a missense mutation $(\mathrm{GGC} \rightarrow \mathrm{GAC})$ at codon 305 in exon 7 of the MEN1 gene that predicts an amino acid change from glycine to aspartic acid (G305D). This mutation segregated with primary hyperparathyroidism in the kindred, and, in addition, there were two asymptomatic mutant-gene carriers at relatively advanced ages. In contrast, the mutation was not detected in genomic DNA from five unaffected individuals and from 50 healthy subjects. The LOH study showed a loss of the wild-type allele, which confirmed that a functional defect of the MEN1 gene product, menin, is etiological for FIHP.

Conclusions: FIHP is a genetically heterogeneous disease with a subset linked to MEN1, most likely representing a variant of MEN1. The late onset and the reduced penetrance of disease found in this kindred may be related to the site and the type of mutation, although the precise mechanism involved is unknown at present.
\end{abstract}

European Journal of Endocrinology 142 138-143

\section{Introduction}

Multiple endocrine neoplasia type 1 (MEN1) is an autosomal dominant inherited disorder with a high degree of penetrance and some variability of expression (1). Affected individuals typically have tumors of the parathyroid gland, endocrine pancreas and anterior pituitary. The responsible gene, MEN1, was mapped to chromosomal region $11 \mathrm{q} 13$ (2), and recently identified by positional cloning $(3,4)$. Since loss of heterozygosity (LOH) of the MEN1 locus frequently occurs in MEN1related tumors $(2,5)$ as well as in sporadic parathyroid tumors $(6,7)$, the MEN1 gene has been considered to be a tumor suppressor gene. In the majority of MEN1 patients, a wide variety of germline mutations of the MEN1 gene have been demonstrated, thus supporting the Knudson hypothesis (3, 4, 8-10).

Familial isolated hyperparathyroidism (FIHP) is a rare heritable disorder characterized by hyperparathyroidism with no evidence of hyperfunction of any other endocrine tissues (11). Similar to MEN1, its mode of inheritance is usually autosomal dominant. Whether FIHP may exist as a distinct disease entity or represents a variant of any of the known MEN1s is controversial. Genetic analysis of one FIHP family (12) produced, though inconclusive (13), positive linkage results in the MEN1 region suggesting that it is a variant of MEN1. Mutation analysis conducted in subsequent studies, however, gave variable results $(6,14-18)$. We describe here a Japanese family with FIHP and evaluate their clinical, pathological and genetic profiles.

\section{Subjects and methods}

\section{Subjects}

The FIHP kindred (Fig. 1) is a Japanese family and is currently residing in Kanagawa Prefecture, Japan. All 


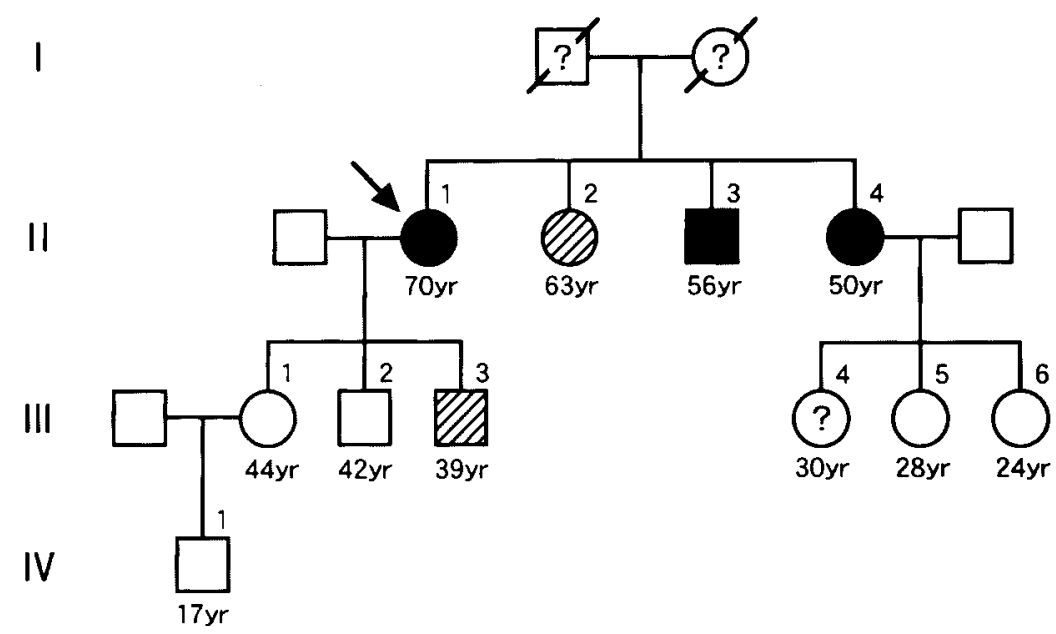

Figure 1 Pedigree and phenotypes of the kindred with FIHP. Filled symbols $(\mathbf{\square}, \mathbf{\bullet})$ indicate members affected with hyperparathyroidism; open symbols $(\square, \bigcirc)$, unaffected; hatched symbols (hatched square, hatched circle), unaffected members who are mutant-gene carriers; members with an unknown status are marked with a question mark. Ages of family members at the end of the study are given under their symbols. An arrow indicates the proband. but one living members were screened with biochemical examinations including serum calcium, phosphate, albumin, intact parathyroid hormone (PTH) and prolactin (PRL). Because of the absence of symptoms, individual III-4 refused to participate in the study.

The proband (II-1) is a female who at age 64 was found to have persistent hypercalcemia after right mastectomy for breast cancer. Further investigations confirmed primary hyperparathyroidism, and an abnormal parathyroid gland (the left superior gland) was removed by surgery. The gland weighed $0.9 \mathrm{~g}$, and the histology was consistent with chief cell hyperplasia. Her serum calcium declined to within the normal range after the operation, but again tended to rise above normal with an elevated plasma intact PTH level at a 6-month postoperative check-up. The patient was followed up for the succeeding 5 years, and a ${ }^{99 \mathrm{~m}} \mathrm{Tc}$-sestamibi scan now shows an increased uptake into the right inferior parathyroid gland. She has no evidence of other MEN-related neoplasia assessed by radiological and hormonal examinations. Her parents were not known to have had any history of primary hyperparathyroidism.

\section{Germline mutation analysis}

Blood was drawn from 10 members of the family and from 50 healthy Japanese people after informed consent was obtained. Mutations in the MEN1 gene were analyzed as previously reported (14) with a minor modification. In brief, genomic DNA was extracted from blood samples with a QIAamp blood kit (Qiagen, Hilden, Germany). All protein-coding regions of exons 2 through 10 of the MEN1 gene were amplified by PCR in a $50 \mu \mathrm{l}$ reaction mixture containing approximately $150 \mathrm{ng}$ genomic DNA, one of nine pairs of primers and Taq DNA polymerase (Takara Taq, Takara, Tokyo, Japan). The PCR conditions used an initial denaturation at $95^{\circ} \mathrm{C}$ for $1 \mathrm{~min}$, followed by 31 cycles at $95^{\circ} \mathrm{C}$ for
$1 \mathrm{~min}$, at $64-68^{\circ} \mathrm{C}$ for $1 \mathrm{~min}$ and at $72^{\circ} \mathrm{C}$ for $2 \mathrm{~min}$, with a final extension at $72{ }^{\circ} \mathrm{C}$ for $5 \mathrm{~min}$. PCR products were purified with a QIAquick PCR purification kit (Qiagen). Nucleotide sequences were then determined by direct sequencing of the PCR products using a DNA sequencing kit (Dye Terminator Cycle Sequencing Ready Reaction, Perkin-Elmer, Foster City, CA, USA) and an automated DNA sequencer (ABI PRISM310, Perkin-Elmer).

\section{LOH study}

Hyperplastic parathyroid gland was obtained from a sister (II-4 in Fig. 1) of the proband at the time of surgery. Fresh tissue was snap frozen in liquid nitrogen and stored at $-70{ }^{\circ} \mathrm{C}$ until later molecular analysis. DNA was extracted with a QIAamp tissue kit (Qiagen), amplified by PCR and sequenced directly as described above for genomic DNA.

Microsatellite length polymorphism around the MEN1 locus was analyzed using polymorphic DNA markers on chromosome 11q13, PYGM and D11S4940, as described previously (19). PYGM and D11S4940 are located centromeric and telomeric, respectively, to the MEN1 gene. Genomic and tissue DNA were amplified by PCR with a pair of primers, one of which was labeled with fluorescein. The amount and the size of the PCR products were determined by electrophoresis followed by measurement of fluorescence intensity with an automated genetic analyzer (ABI PRISM310).

\section{Results}

\section{Family screening}

Two new patients with primary hyperparathyroidism were discovered in this family. Biochemical profiles of these patients including the proband are given in Table 1. 
Table 1 Preoperative basal serum or plasma levels or calcium, phosphate and hormones for the three affected members in the present kindred*.

\begin{tabular}{|c|c|c|c|c|}
\hline Case & II-1 & II-3 & II-4 & Normal range \\
\hline $\mathrm{Age}^{\star \star} / \mathrm{sex}$ & $64 / F$ & $56 / \mathrm{M}$ & $50 / F$ & - \\
\hline Calcium (mmol/l) & 2.9 & 2.7 & 3.3 & $2.2-2.5$ \\
\hline Phosphate (mmol/l) & 0.6 & 0.7 & 0.7 & $0.8-1.5$ \\
\hline Intact PTH (ng/l) & 112 & 55 & 144 & $10-60$ \\
\hline $\mathrm{PRL}(\mu \mathrm{g} / \mathrm{l})$ & 4.9 & 1.7 & 6.1 & $\mathrm{~F}: 1.4-14.0, \mathrm{M}: 1.5-9.7$ \\
\hline $\mathrm{GH}(\mu \mathrm{g} / \mathrm{l})$ & 1.78 & 0.40 & 1.25 & $\mathrm{~F}: 0.28-8.70, \mathrm{M}:<1.46$ \\
\hline $\mathrm{TSH}(\mathrm{mU} / \mathrm{l})$ & 1.65 & 2.87 & 2.15 & $0.40-4.00$ \\
\hline Free $\mathrm{T}_{4}(\mathrm{pmol} / \mathrm{l})$ & 12.9 & 15.4 & 12.9 & $12.9-23.2$ \\
\hline $\mathrm{ACTH}(\mathrm{pmol} / \mathrm{l})$ & 5.3 & 12.6 & 4.4 & $<13.2$ \\
\hline Cortisol (nmol/l) & 281 & 287 & 265 & $155-588$ \\
\hline $\mathrm{LH}(\mathrm{IU} / \mathrm{I})$ & 13.7 & 4.4 & 14.5 & $\mathrm{~F}: 4.2-79.6, \mathrm{M}: 1.1-8.8$ \\
\hline FSH $(\mathrm{IU} / \mathrm{I})$ & 38.6 & 12.0 & 79.2 & $F: 12.6-235.7, M: 1.8-13.6$ \\
\hline Testosterone (nmol/l) & - & 21.5 & - & $11.1-35.7$ \\
\hline Insulin (pmol/l) & 53.8 & 35.9 & 63.1 & $21.5-122.0$ \\
\hline Glucagon (ng/l) & 102 & 133 & 108 & $70-160$ \\
\hline Gastrin (ng/l) & 140 & 42 & 47 & $30-140$ \\
\hline
\end{tabular}

*Blood samples were collected after an overnight fast.

${ }^{* *}$ Ages at the time of examination.

$\mathrm{GH}=$ growth hormone; $\mathrm{TSH}=$ thyrotropin; $\mathrm{T}_{4}=$ thyroxine; $\mathrm{ACTH}=$ adrenocorticotropin; $\mathrm{LH}=$ luteinizing hormone; $\mathrm{FSH}=$ follicle-stimulating hormone.

A sister of the proband (II-4) had a history of renal colic. On examination, her serum calcium and plasma intact PTH concentrations were markedly elevated. ${ }^{99 \mathrm{~m}} \mathrm{Tc}$-sestamibi scintigraphy revealed enlargement of the left superior parathyroid gland, which was removed by surgery. The gland weighed $4.2 \mathrm{~g}$, and the pathological diagnosis was chief cell hyperplasia. Her serum calcium levels returned to normal after the operation. The brother of the proband (II-3) had mild hypercalcemia with an upper limit of normal plasma intact PTH level, although he had no symptoms or signs of primary hyperparathyroidism. A ${ }^{99} \mathrm{~m}$ Tc-sestamibi scan showed an increased uptake in the right inferior parathyroid gland. In both patients, circulating levels of anterior pituitary hormones, insulin, glucagon and gastrin were, on the other hand, normal, and imaging studies for the pituitary, pancreas, kidney, mandible and maxilla gave negative results. The clinical and biochemical screenings for primary hyperparathyroidism, MEN1 or hyperparathyroidism-jaw tumor (HPT-JT) syndrome were negative for another seven family members.

\section{Germline mutation analysis}

In all of the three affected and in two unaffected members in this family, analysis of germline DNA showed a missense mutation $(\mathrm{GGC} \rightarrow \mathrm{GAC})$ at codon 305 in exon 7 of the MEN1 gene (Fig. 2) that results in a glycine to aspartic acid substitution (G305D). The mutation was confirmed to be heterozygous by identifying both the wild-type and mutant sequences of the PCR products. In contrast, this mutation was not detected in genomic DNA from five unaffected family members (Fig. 1) and from 50 healthy subjects.

\section{LOH study}

LOH was sought in the hyperplastic parathyroid gland from an affected member in this family. Analysis of the tissue DNA revealed that the G305D mutant allele was predominant with a loss of the wild-type allele (Fig. 2). The result is in agreement with $\mathrm{LOH}$ on 11q13 in this abnormal parathyroid gland. Further, microsatellite polymorphism analysis showed the reduced fluorescence intensity at each polymorphic site for one of the alleles in tissue DNA (Fig. 3). The retained allele cosegregated with the G305D mutation in family members, indicating that the wild-type allele is lost in the tissue (data not shown).

\section{Discussion}

Three members from two generations in this kindred were found to have primary hyperparathyroidism. None of the patients had clinical or biochemical evidence of MEN1, MEN2 or HPT-JT syndrome. Thus this family fulfills the diagnostic criteria for FIHP. It may be argued that the family represents an early stage of MEN1, but not FIHP, since primary hyperparathyroidism is the first and most common lesion during the natural history of MEN1 (1). The possibility may be unlikely for two reasons. First, the onset of primary hyperparathyroidism is at relatively advanced ages in affected individuals. Secondly, there are two MEN1 mutantgene carriers (II-2 and III-3 in Fig. 1), at 63 and 39 years of age respectively, who have not shown any biochemical signs of primary hyperparathyroidism despite careful screening. The late onset of disease and the reduced penetrance is in sharp contrast to MEN1, 
A

$$
\text { 5'- C CA G G } \stackrel{\downarrow}{\downarrow} \text { CA T T G C-3' }
$$

A

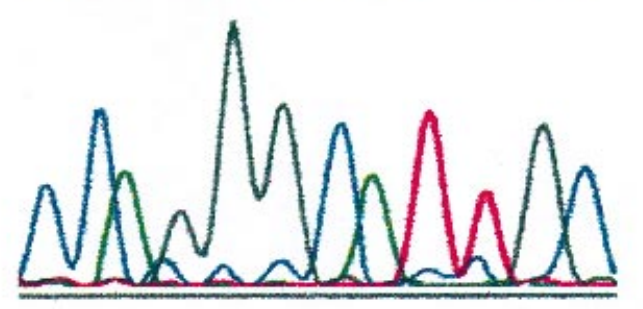

$$
\text { 5-C CA G G } \underset{A}{\downarrow} \text { CAT T G C - } 3^{\prime}
$$

B
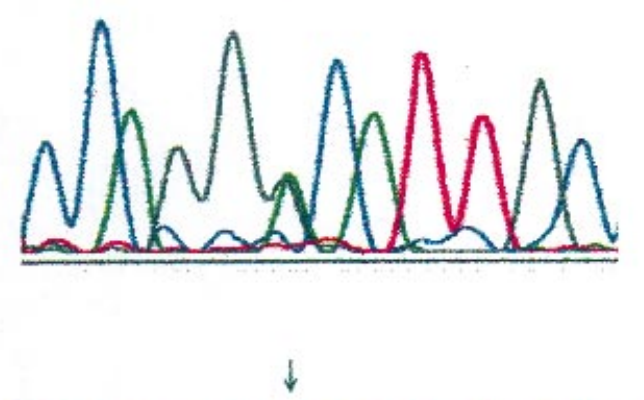

5'-C CA G G A CA T T G C - $3^{\prime \prime}$

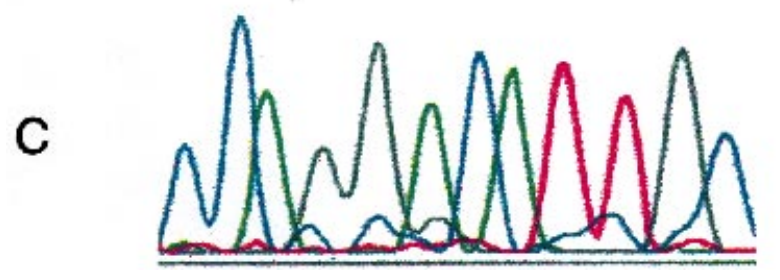

Figure 2 Direct sequence analyses showing a missense mutation at codon 305, from GGC to GAC (G305D), in exon 7 of the MEN1 gene and a loss of the wild-type allele in the hyperplastic parathyroid tissue of an affected member (II-4). (A) Blood cell DNA from a normal individual; (B) blood cell DNA from an affected member (II-4); (C) DNA from the hyperplastic parathyroid tissue. Nucleotide position 305 is indicated by an arrow.

where primary hyperparathyroidism occurs in over $95 \%$ of cases, and the age-related penetrance was estimated to be 98 and $100 \%$ at 40 and 60 years of age respectively (9).

Analysis of the MEN1 gene in the hyperplastic parathyroid gland from a family member showed a loss of wild-type allele at chromosome 11q13. The result indicates the involvement of the MEN1 gene, a putative tumor suppressor gene, in the genesis of parathyroid lesions in this kindred. In five family members including three affected individuals, direct sequencing of genomic DNA revealed a missense
A.

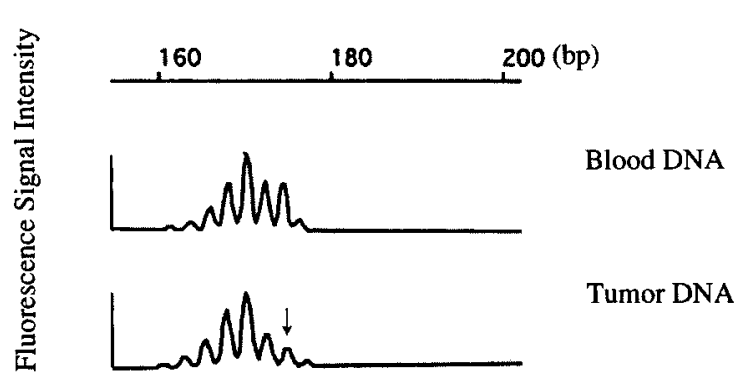

B.

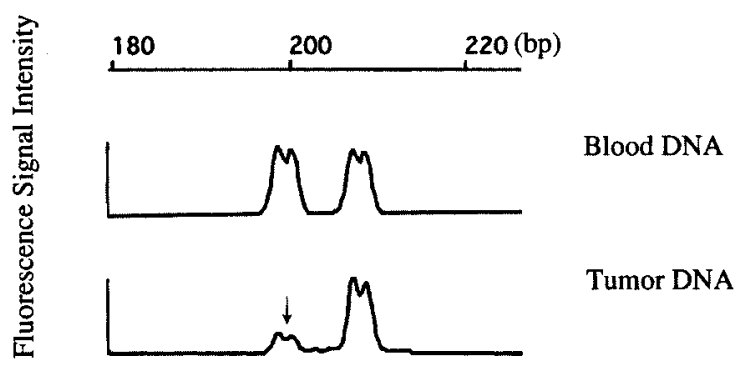

Figure 3 Microsatellite polymorphism analysis using polymorphic DNA markers, PYGM (A) and D11S4940 (B). Arrows denote peaks with reduced fluorescence intensity in tumor compared with blood DNA.

mutation at codon 305 in exon 7 of the MEN1 gene. This mutation was not detected in genomic DNA from five unaffected family members and from 50 healthy subjects, supporting the view that it is not likely to be benign polymorphism. Thus we conclude that the germline mutation causes a familial predisposition to excessive cell proliferation in the parathyroid gland and that the loss of function of the MEN1-encoded protein, menin, is etiological for FIHP in this kindred. Recently, Agarwal et al. (20) demonstrated that menin represses JunD-activated transcription by direct binding to JunD. MEN1 missense mutations in a limited region of menin may then disrupt menin-JunD interaction and may finally lead to tumor formation, although the precise mechanism remains obscure.

Whether FIHP is a separate clinical entity or a variant of MEN1 has been controversial. Linkage to MEN1 was implicated in one FIHP family, but without conclusive evidence (12). In subsequent studies, some investigators showed germline mutations of the MEN1 gene in clinically apparent FIHP families $(14,17)$, whereas others could not $(6,15,16)$. In former studies, however, $\mathrm{LOH}$ analysis was not performed and, because of the relatively young ages of the patients examined, the possibility that they are at early stages of MEN1 could not be completely excluded. Very recently, Teh et al. (18) reported a missense mutation (E255K) in the MEN1 gene in an FIHP family, and found a loss of the wild-type allele in removed parathyroid tumors. The present study 
as well as theirs clearly shows that FIHP can occur as a variant of MEN1. FIHP is, therefore, a genetically heterogeneous disease. A subset is linked to MEN1, most likely representing a variant of MEN1. Some FIHP families may genetically be assigned to the locus of the HPT-JT syndrome (21). In fact, a family initially reported as FIHP was found to have HPT-JT syndrome in later years (22). It is uncertain at present whether FIHP families having genetic defects other than the MEN1 or HPT-JT gene may exist.

The MEN1 mutation (G305D) found in the present study has never been reported either in MEN1 families or in sporadic counterparts of MEN1-related tumors, while other missense mutations in the same exon (A309P and R314P) were documented in two MEN1 families $(8,10)$. The reason why missense mutations of the MEN1 gene located in close proximity are associated with typical MEN1 on the one hand, and cosegregate with FIHP on the other, is unclear. Of relevance in this regard is the finding that, in familial adenomatous polyposis (23) and familial retinoblastoma (24), kindreds with low penetrance and expressivity show gene mutations resulting in the splicing-out of the mutation site in a fraction of mRNA and in the residual production of wild-type transcripts from the mutant allele. Viewed in this light, the late onset and the reduced penetrance of disease observed in the present family may be explained by the site of the mutation. The mutation is, indeed, at codon 305 in exon 7, close to the preceding intron, and hence could be a target for alternate splicing. Since, however, no genotypephenotype correlation has been established in MEN1 (8-10), family members carrying the mutation should have careful follow-up as potential MEN1 patients, to determine if they may develop any other endocrine abnormalities in the future.

\section{Acknowledgements}

This work was partly supported by Grants-in-Aid from the Ministry of Health and Welfare, Japan, for Cancer Research (10-28) and the Second-Term Comprehensive Ten-Year Strategy for Cancer Control.

\section{References}

1 Brandi ML, Marx SJ, Aurbach GD \& Fitzpatrick LA. Familial multiple endocrine neoplasia type 1: a new look at pathophysiology. Endocrine Reviews 19878 391-405.

2 Larsson C, Skogseid B, Öberg K, Nakamura Y \& Nordenskjöld M. Multiple endocrine neoplasia type 1 gene maps to chromosome 11 and is lost in insulinoma. Nature $198833285-87$.

3 Chandrasekharappa SC, Guru SC, Manickam P, Olufemi SE, Collins FS, Emmert-Buck MR et al. Positional cloning of the gene for multiple endocrine neoplasia-type 1. Science $1997276404-$ 407.

4 The European Consortium on MEN1. Identification of the multiple endocrine neoplasia type 1 (MEN1) gene. Human Molecular Genetics 19976 1177-1183.
5 Thakker RV, Bouloux P, Wooding C, Chotai K, Broad PM, Spurr NK et al. Association of parathyroid tumors in multiple endocrine neoplasia type 1 with loss of alleles on chromosome 11. New England Journal of Medicine 1989321 218-224.

6 Farnebo F, Teh BT, Kytölä S, Svensson A, Phelan C, Sandelin K et al. Alterations of the MEN1 gene in sporadic parathyroid tumors. Journal of Clinical Endocrinology and Metabolism 199883 2627-2630.

7 Carling T, Correa P, Hessman O, Hedberg J, Skogseid B, Lindberg D et al. Parathyroid MEN1 gene mutations in relation to clinical characteristics of nonfamilial primary hyperparathyroidism. Journal of Clinical Endocrinology and Metabolism 199883 29602963.

8 Agarwal SK, Kester MB, Debelenko LV, Heppner C, Emmert-Buck MR, Skarulis MC et al. Germline mutations of the MEN1 gene in familial multiple endocrine neoplasia type 1 and related states. Human Molecular Genetics 19976 1169-1175.

9 Bassett JHD, Forbes SA, Pannett AAJ, Lloyd SE, Christie PT, Wooding $\mathrm{C}$ et al. Characterization of mutations in patients with multiple endocrine neoplasia type 1. American Journal of Human Genetics 199862 232-244.

10 Giraud S, Zhang CX, Serova-Sinilnikova O, Wautot V, Salandre J, Buisson $\mathrm{N}$ et al. Germ-line mutation analysis in patients with multiple endocrine neoplasia type 1 and related disorders. American Journal of Human Genetics 199863 455-467.

11 Huang S-M, Duh Q-Y, Shaver J, Siperstein AE, Kraimps J-L \& Clark OH. Familial hyperparathyroidism without multiple endocrine neoplasia. World Journal of Surgery $19972122-$ 29.

12 Kassem M, Zhang X, Brask S, Eriksen EF, Mosekilde L \& Kruse TA. Familial isolated primary hyperparathyroidism. Clinical Endocrinology 199441 415-420.

13 Wassif WS \& Peters TJ. Familial isolated primary hyperparathyroidism. Clinical Endocrinology $199542441-442$.

14 Shimizu S, Tsukada T, Futami H. Ui K, Kameya T, Kawanaka M et al. Germline mutations of the MEN1 gene in Japanese kindred with multiple endocrine neoplasia type 1. Japanese Journal of Cancer Research 199788 1029-1032.

15 Tanaka C, Yoshimoto K, Yamada S, Nishioka H, Ii S, Moritani M et al. Absence of germ-line mutations of the multiple endocrine neoplasia type 1 (MEN1) gene in familial pituitary adenoma in contrast to MEN1 in Japanese. Journal of Clinical Endocrinology and Metabolism 199883 960-965.

16 Teh BT, Kytölä S, Farnebo F, Bergman L, Wong FK, Weber G et al. Mutation analysis of the MEN1 gene in multiple endocrine neoplasia type 1 , familial acromegaly and familial isolated hyperparathyroidism. Journal of Clinical Endocrinology and Metabolism $1998832621-2626$.

17 Ohye H, Sato M, Matsubara S, Miyauchi A, Imachi H, Murao K et al. Germline mutation of the multiple endocrine neoplasia type 1 (MEN1) gene in a family with primary hyperparathyroidism. Endocrine Journal $199845719-723$.

18 Teh BT, Esapa CT, Houlston R, Grandell U, Farnebo F, Nordenskjöld $\mathrm{M}$ et al. A family with isolated hyperparathyroidism segregating a missense MEN1 mutation and showing loss of the wild-type alleles in the parathyroid tumors. American Journal of Human Genetics 199863 1544-1549.

19 Kishi M, Tsukada T, Shimizu S, Futami H, Ito Y, Kanbe M et al. A large germline deletion of the MEN1 gene in a family with multiple endocrine neoplasia type 1. Japanese Journal of Cancer Research $1998891-5$.

20 Agarwal SK, Guru SC, Heppner C, Erdos MR, Collins RM, Park SY et al. Menin interacts with the AP1 transcription factor JunD and represses JunD-activated transcription. Cell $199996143-$ 152.

21 Teh BT, Farnebo F, Twigg S, Höög A, Kytölä S, Korpi-Hyövälti E et al. Familial isolated hyperparathyroidism maps to the hyperparathyroidism-jaw tumor locus in 1q21-q32 in a subset of families. Journal of Clinical Endocrinology and Metabolism 1998 83 2114-2120. 
22 Wassif WS, Farnebo F, Teh BT, Moniz CF, Li F-Y, Harrison JD et al. Genetic studies of a family with hereditary hyperparathyroidism-jaw tumour syndrome. Clinical Endocrinology 199950 191-196.

23 Curia MC, Esposito DL, Aceto G, Palmirotta R, Crognale S, Valanzano R et al. Transcript dosage effect in familial adenomatous polyposis: model offered by two kindreds with exon 9 APC gene mutations. Human Mutation 199811 197-201.
24 Schubert EL, Strong LC \& Hansen MF. A splicing mutation in RB1 in low penetrance retinoblastoma. Human Genetics 1997100 557-563.

Received 19 May 1999

Accepted 9 September 1999 